\title{
Building damage from the 2011 Great East Japan tsunami: quantitative assessment of influential factors
}

\author{
A new perspective on building damage analysis
}

\author{
Natt Leelawat $\cdot$ Anawat Suppasri $\cdot$ Ingrid Charvet $\cdot$ Fumihiko Imamura
}

Received: 20 August 2013/ Accepted: 7 February 2014/Published online: 28 February 2014

(C) The Author(s) 2014. This article is published with open access at Springerlink.com

\begin{abstract}
Based on the classification provided by the Ministry of Land, Infrastructure, Transport and Tourism (MLIT), the damage level of buildings impacted by the 2011 Great East Japan tsunami can be separated into six levels (from minor damage to washed away). The objective of this paper is to identify the significant predictor variables and the direction of their potential relationship to the damage level in order to create a predicting formula for damage level. This study used the detailed data of damaged buildings in Ishinomaki city, Miyagi prefecture, Japan, collected by MLIT. The explanatory variables tested included the inundation depth, number of floors, structural material, and function of the building. Ordinal regression was applied to model the relationship between the ordinal outcome variable (damage level) and the predictors. The findings indicated that inundation depth, structural material, and function of building were significantly associated with the damage level. In addition to this new type of model, this research provides a valuable insight into the relative influence of different factors on building damage and suggestions that may help to revise the classification of current standards. This study can contribute to academic tsunami research by assessing the contribution of different variables to the observed damage using new approaches based on statistical analysis and regression. Moreover,
\end{abstract}

N. Leelawat $(\bowtie)$

Department of Industrial Engineering and Management, Tokyo Institute of Technology, 2-12-1-W9-66, Ookayama, Meguro-ku, Tokyo 152-8552, Japan

e-mail: leelawat.n.aa@m.titech.ac.jp

A. Suppasri · F. Imamura

International Research Institute of Disaster Science, Tohoku University, 6-6-11-1104,

Aramaki, Aoba-ku, Sendai, Japan

e-mail: suppasri@irides.tohoku.ac.jp

F. Imamura

e-mail: imamura@irides.tohoku.ac.jp

I. Charvet

Earthquake and People Interaction Centre, University College London, Gower Street,

London WC1E 6BT, UK

e-mail: i.charvet@ucl.ac.uk 
practical applications of these results include understanding of the predominant factors driving tsunami damage to structures, implementation of the relevant variables into the proposed, or alternative model in order to improve current damage predictions by taking into account not only inundation depth, but also variables such as structural material and function of building.

Keywords 2011 Great East Japan tsunami · Building damage level · Ordinal regression · Prediction

\section{Introduction}

According to the International Disaster Database (2013), the 2011 Great East Japan earthquake and tsunami caused the highest estimated damage, USD 201 billion, among other natural disasters during 1990-2012. At 14:49 JST on March 11, 2011, a M9.0 earthquake was recorded, and triggered large and powerful tsunami waves which attacked Japan. The East coast of Japan suffered extensive damage and the destruction of more than 400,000 buildings (National Police Agency 2011).

The objective of this study is to provide a quantitative assessment of the influence from the factors that appear to be determinant on tsunami damage, namely the inundation depth, the coastal topography, the number of floors, the structural material, and the function of buildings (Suppasri et al. 2012a, c, 2013, 2014; etc.). Such an assessment allows for the ranking of such factors by order of importance in their contribution to the damage level. In addition, it is possible to suggest a relationship between the significant variables and the estimated damage level.

In Sect. 2, a review of the literature on tsunami damage prediction is carried out, highlighting the usual damage factors considered. In Sect. 3, the study area is presented, followed by a description of the ordinal regression methodology (Sect. 4). Section 5 covers the data collection and analysis. Finally, the results, their applicability, and their implications are discussed in Sect. 6.

\section{Literature review}

\subsection{Building damage due to tsunami inundation depth}

Shuto (1993) studied the relationship between a range of tsunami inundation depths and building damage using the information from historical tsunamis. For example, it was found that if the tsunami inundation depth is higher than 2-m wooden houses may collapse, for an inundation depth of $8 \mathrm{~m}$, reinforced concrete buildings may collapse. Subsequent studies confirmed such results: Ruangrassamee et al. (2006) found from the data of the 2004 Indian Ocean tsunami that a 2-m inundation depth can destroy a wooden house, and Reese et al. (2007) found this same inundation depth would destroy unreinforced brick buildings. After Shuto (1993), the damage criteria for each structural material against a range of tsunami inundation depths have been investigated further (Suppasri et al. 2013). Suppasri et al. (2014) also studied the damage criteria by using coastal topography categorizing into ria coast and plain coast while Charvet et al. (2014) categorized by the geographical 
environment into plain, terrain (i.e., "a narrow coast backed up by high topography"), and a river. Table 1 summarizes the research related to building damage criteria on structural and inundation depth. Table 2 summarizes the research related to building damage criteria on coastal topography and inundation depth. In addition, "tsunami fragility" was introduced as a new measure for estimating tsunami damage to buildings (Koshimura et al. 2009b). Some studies proposed fragility curves for structural destruction from tsunami for many events such as the 1993 Okushiri tsunami in Japan (Koshimura et al. 2009a; Koshimura and Kayaba 2010; Suppasri et al. 2012b), the 2004 Indian Ocean tsunami (study area: Sri Lanka) (Muora and Nakazato 2010), Banda Ache, Indonesia (Koshimura et al. 2009c) and Phuket and Phang Nga, Thailand (Suppasri et al. 2011), the 2009 American Samoan tsunami (Gokon et al. 2011), the 2010 Chilean tsunami (study area: Dichato, Chile) (Mas et al. 2012), and the 2011 Great East Japan tsunami (study area: Miyagi prefecture, whole of Japan and Ishinomaki city) (Suppasri et al. 2012c, 2013, 2014, respectively).

\subsection{Vulnerability of buildings as estimated by the Papathoma tsunami vulnerability assessment method (PTVA)}

The Papathoma tsunami vulnerability assessment method (PTVA) was developed by Papathoma et al. (2003). Based on the importance of characteristics of buildings identified by previous field surveys of tsunami events and calculations and using a multi-criteria evaluation method, Papathoma et al. (2003) set weight factors for various criteria according to their relative importance as follows: (1) "building material" (weight factor 7), (2) "row" (weight factor 6), (3) "surrounding" (weight factor 5), (4) "condition of ground floor" (weight factor 4), (5) "number of floors" (weight factor 3), (6) "sea defense" (weight factor 2), and (7) "natural environment" (weight factor 1) (Papathoma et al. 2003). They formulated the vulnerability of each building (BV) as follows:

$$
\mathrm{BV}=(7 \times a)+(6 \times b)+(5 \times c)+(4 \times d)+(3 \times e)+(2 \times f)+(1 \times g)
$$

In Eq. (1), $a$ is the standardized score (i.e., raw score of the building/maximum raw score) of building material; $b$ is the standardized score of row of the building; $c$ is the standardized score of number of floors; $d$ is the standardized score of building surroundings; $e$ is the standardized score of ground floor; $f$ is the standardized score of sea defense in front of the building; and $g$ is the standardized score of width of the intertidal zone in front of the building. PTVA-3 is a revised version of PTVA, which has been tested at Maroubra, Sydney (Dall'Osso et al. 2009a, b).

Moreover, previous studies (Papathoma and Dominey-Howes 2003; Papathoma et al. 2003) show the importance of building physical parameters and their surroundings in analyzing building damage by tsunami, thus such parameters will also be considered in this study. Also, we included other parameters (i.e., inundation depth, coastal topography, function of the building) following Koshimura et al. (2009b), Shuto (1993), and Suppasri et al. (2012a, b, 2013, 2014) in our study.

\section{Study area}

Following the 2011 Great East Japan Earthquake and Tsunami, among the 251,301 buildings surveyed by the Ministry of Land, Infrastructure, Tourism and Transport (MLIT), more than $25 \%$ (63,605 buildings) were in Ishinomaki city. According to the damage and 
Table 1 Summary of building damage criteria (structural material and inundation depth)

\begin{tabular}{|c|c|c|c|c|}
\hline Author(s) & Event & $\begin{array}{l}\text { Structural } \\
\text { material }\end{array}$ & $\begin{array}{l}\text { Inundation } \\
\text { depth }(\mathrm{m})\end{array}$ & Damage \\
\hline \multirow[t]{4}{*}{ Shuto (1993) } & \multirow{4}{*}{$\begin{array}{l}\text { Historical tsunami in } \\
\text { Japan }\end{array}$} & Wood & 1.0 & Partial damaged \\
\hline & & Wood & 2.0 & Demolished \\
\hline & & $\begin{array}{l}\text { Reinforced } \\
\text { concrete }\end{array}$ & $\approx 4$ & Demolished \\
\hline & & Stone & $\approx 2$ & Demolished \\
\hline \multirow{4}{*}{$\begin{array}{l}\text { Ruangrassamee } \\
\text { et al. (2006) }\end{array}$} & \multirow{4}{*}{$\begin{array}{l}2004 \text { Indian Ocean } \\
\text { tsunami }\end{array}$} & Wood & 2.0 & Collapsed \\
\hline & & $\begin{array}{l}\text { Reinforced } \\
\text { concrete }\end{array}$ & 2.0 & $\begin{array}{l}\text { Secondary member } \\
\text { damaged (e.g., wall, roof) }\end{array}$ \\
\hline & & $\begin{array}{l}\text { Reinforced } \\
\text { concrete }\end{array}$ & 3.0 & $\begin{array}{l}\text { Primary member damaged } \\
\text { (e.g., columns, beams) }\end{array}$ \\
\hline & & $\begin{array}{l}\text { Reinforced } \\
\text { concrete }\end{array}$ & 7.0 & Completely destroyed \\
\hline $\begin{array}{l}\text { Reese et al. } \\
\quad(2007)\end{array}$ & 2006 Java tsunami & $\begin{array}{l}\text { Unreinforced } \\
\text { brick }\end{array}$ & 2.0 & Collapsed \\
\hline \multirow[t]{3}{*}{$\begin{array}{l}\text { Reese et al. } \\
\text { (2011) }\end{array}$} & \multirow[t]{3}{*}{$\begin{array}{l}2009 \text { South Pacific } \\
\text { tsunami }\end{array}$} & $\begin{array}{l}\text { Reinforced } \\
\text { concrete }\end{array}$ & 2.0 & $\begin{array}{l}\text { Secondary member } \\
\text { damaged (e.g., wall, roof) }\end{array}$ \\
\hline & & $\begin{array}{l}\text { Reinforced } \\
\text { concrete }\end{array}$ & 3.0 & $\begin{array}{l}\text { Primary member damaged } \\
\text { (e.g., columns, beams) }\end{array}$ \\
\hline & & $\begin{array}{l}\text { Reinforced } \\
\text { concrete }\end{array}$ & 7.0 & Complete destroyed \\
\hline \multirow[t]{3}{*}{$\begin{array}{l}\text { Valencia et al. } \\
\text { (2011) }\end{array}$} & \multirow[t]{3}{*}{$\begin{array}{l}2004 \text { Indian Ocean } \\
\text { tsunami }\end{array}$} & $\begin{array}{l}\text { Reinforced } \\
\text { concrete }\end{array}$ & 2.0 & $\begin{array}{l}\text { Secondary member } \\
\text { damaged (e.g., wall, roof) }\end{array}$ \\
\hline & & $\begin{array}{l}\text { Reinforced } \\
\text { concrete }\end{array}$ & 3.0 & $\begin{array}{l}\text { Primary member damaged } \\
\text { (e.g., columns, beams) }\end{array}$ \\
\hline & & $\begin{array}{l}\text { Reinforced } \\
\text { concrete }\end{array}$ & 7.0 & Complete destroyed \\
\hline \multirow{5}{*}{$\begin{array}{l}\text { Matsutomi and } \\
\text { Harada (2010) }\end{array}$} & \multirow{5}{*}{$\begin{array}{l}2009 \text { American } \\
\text { Samoa tsunami }\end{array}$} & Wood & 1.5 & Partially damaged \\
\hline & & Wood & 2.0 & Destroyed \\
\hline & & $\begin{array}{l}\text { Reinforced } \\
\text { concrete }\end{array}$ & 8.0 & Destroyed \\
\hline & & $\begin{array}{l}\text { Stone, brick, } \\
\text { concrete } \\
\text { block }\end{array}$ & 3.0 & Partially damaged \\
\hline & & $\begin{array}{l}\text { Stone, brick, } \\
\text { concrete } \\
\text { block }\end{array}$ & 7.0 & Destroyed \\
\hline \multirow{4}{*}{$\begin{array}{l}\text { Suppasri et al. } \\
\text { (2012a, c, 2013) }\end{array}$} & \multirow{4}{*}{$\begin{array}{l}2011 \text { Great East Japan } \\
\text { tsunami (plain coast } \\
\text { in Sendai and } \\
\text { Ishinomaki) }\end{array}$} & Wood & 2.5 & Minor damaged \\
\hline & & Wood & 3.0 & Moderate damaged \\
\hline & & Wood & 4.0 & Major damaged \\
\hline & & Wood & 4.5 & Complete damaged \\
\hline \multirow{4}{*}{$\begin{array}{l}\text { Suppasri et al. } \\
\text { (2012c, 2013) }\end{array}$} & \multirow{4}{*}{$\begin{array}{l}2011 \text { Great East Japan } \\
\text { tsunami (all Tohoku } \\
\text { region) }\end{array}$} & Wood & 0.5 & Minor/moderate damaged \\
\hline & & Wood & 1 & Major damaged \\
\hline & & Wood & 2 & $\begin{array}{l}\text { Complete damaged/ } \\
\text { collapsed }\end{array}$ \\
\hline & & Wood & 3 & Washed away \\
\hline
\end{tabular}


Table 2 Summary of building damage criteria (coastal topography and inundation depth)

\begin{tabular}{|c|c|c|c|c|}
\hline Author(s) & Event & $\begin{array}{l}\text { Coastal } \\
\text { topography }\end{array}$ & $\begin{array}{l}\text { Inundation depth } \\
\text { (m) }\end{array}$ & Damage \\
\hline \multirow{8}{*}{$\begin{array}{l}\text { Charvet et al. } \\
\text { (2014) }\end{array}$} & \multirow{8}{*}{$\begin{array}{l}2011 \text { Great East Japan } \\
\text { tsunami (all areas of } \\
\text { Ishinomaki) }\end{array}$} & Ria & 1 & Moderate damaged \\
\hline & & Ria & $1-2$ & Major damaged \\
\hline & & Ria & $2-3.5$ & $\begin{array}{l}\text { Collapsed and washed } \\
\text { away }\end{array}$ \\
\hline & & Terrain & 1 & Moderate damaged \\
\hline & & Terrain & $1-2$ & Major damaged \\
\hline & & Terrain & $2-6$ & $\begin{array}{l}\text { Collapsed and washed } \\
\text { away }\end{array}$ \\
\hline & & River & $0-0.5$ & Moderated damaged \\
\hline & & River & $1.5-2$ & Major damaged \\
\hline \multirow{6}{*}{$\begin{array}{l}\text { Suppasri et al. } \\
\text { (2012c, 2013) }\end{array}$} & \multirow{6}{*}{$\begin{array}{l}2011 \text { Great East Japan } \\
\text { tsunami (all areas of } \\
\text { Ishinomaki) }\end{array}$} & Ria & 1 & Moderate damaged \\
\hline & & Ria & $2.5-3$ & Collapsed \\
\hline & & Ria & 5 & Washed away \\
\hline & & Plain & 0.5 & Moderate damaged \\
\hline & & Plain & $2.5-3$ & Collapsed \\
\hline & & Plain & 6 & Washed away \\
\hline
\end{tabular}

$80 \%$ probability

field survey of Suppasri et al. (2014), while the coastal topography can be separated into ria and plain coasts, the residential area is located in the plain area inside the bay (see Fig. 1). Some parts of the city are located along the Sanriku ria coast. According to a visual inspection from satellite images, the amount of washed-away buildings in the area outside the breakwaters was found to be as high as $88.4 \%$ while inside the breakwater protected area, the amount of washed-away buildings was only $42.8 \%$. (Gokon and Koshimura 2012).

\section{Research design and methodology}

\subsection{Methodology}

The present analysis was performed using IBM SPSS version 19. Given the number of predictor variables to be taken into account and the relative simplicity of linear regression analysis comparatively to other regression techniques, multiple linear regression was initially considered as a potential tool for analysis. However, a preliminary inspection of the data revealed that applying multiple linear regression would violate the associated statistical assumptions: According to Crewson (2006), Osborne and Waters (2002), and Seber (1977), the variables should follow a normal distribution, and they should also display homoscedasticity (i.e., the variance of errors needs to be constant), have the mean of errors equal to zero, and be independent (i.e., no trend in the errors). The basic assumption of normally distributed data is violated since normal distributions can only be applied to continuous response variables, so we did not select multiple linear regression. Because our objective is to estimate the damage level, which can be considered as a categorical 


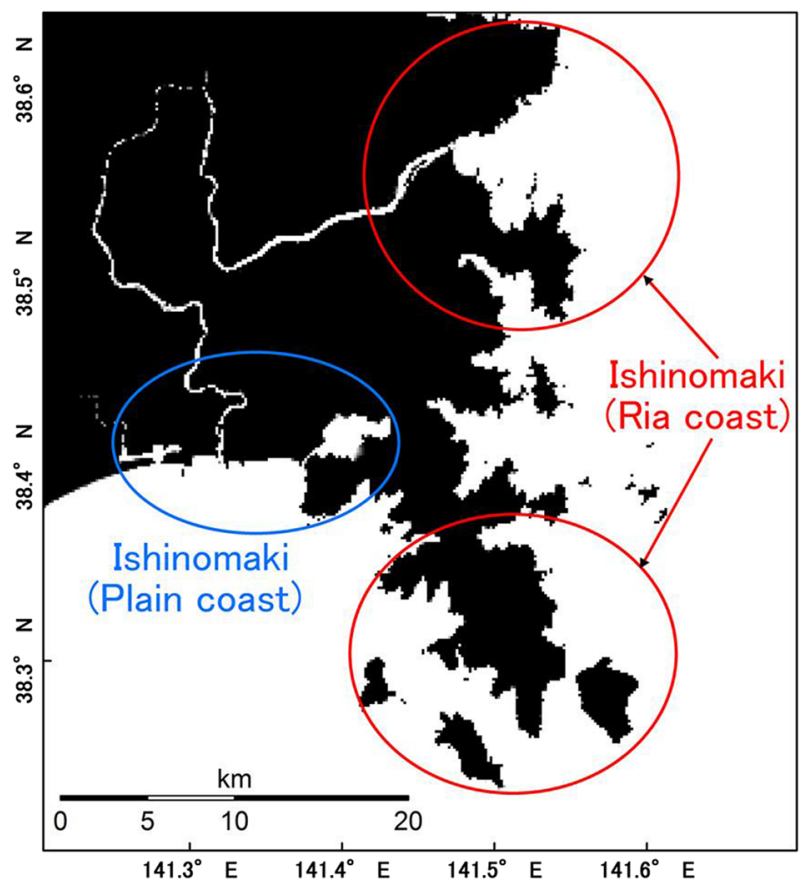

Fig. 1 Ishinomaki city (Suppasri et al. 2014)

dependent and ordinal outcome, ordinal regression is likely to be the most suitable statistical technique for our study.

Ordinal regression is a method used to determine the direction of the relationship between each predictor and a categorical outcome (Chan 2005), taking into account the ordered ("ordinal") nature of such outcome. The strengths of ordinal regression consist in "identifying significant explanatory variables that influence the ordinal outcome," "describing the direction of the relationship between the ordinal outcome and the explanatory variables," and "performing classifications for all levels of the ordinal outcome, subsequently evaluating the validity of the regression model" (Chen and Hughes 2004). Ordinal regression has been often used in medical sciences (Bender and Grouven 1997; Lall et al. 2002; Sutton et al. 2000).

According to previous studies and the available data, the assumed predictor variables are (1) the inundation depth, (2) the coastal topography, (3) the number of floors, (4) the structural material, and (5) the function of the building. The dependent variable is the damage level.

\subsection{Dependent variable: damage level}

Based on the MLIT classification of damage, the degree of building damage can be categorized into six levels: (1) minor damage, (2) moderate damage, (3) major damage, (4) complete damage, (5) collapsed, and (6) washed away. The description and schematically illustration of each damage level are given in Table 3. Besides damaged buildings, there were a small number of buildings with no damage. 


\subsection{Independent variables (predictors)}

The assumed independent variables used in this study were chosen based on previous studies and include: (1) the number of floors (Papathoma and Dominey-Howes 2003), (2) the inundation depth (Koshimura et al. 2009b; Matsutomi and Harada 2010; Reese et al. 2007, 2011; Ruangrassamee et al. 2006; Shuto 1993; Suppasri et al. 2012a, c, 2013; Valencia et al. 2011), (3) the coastal topography (Charvet et al. 2014; Suppasri et al. 2014), (4) the building function (Suppasri et al. 2013, 2014), and (5) the structural material (Papathoma and Dominey-Howes 2003; Papathoma et al. 2003; Suppasri et al. 2013, 2014).

Table 3 Damage levels, classification descriptions, and condition of buildings categorized by MLIT

\begin{tabular}{|c|c|c|c|c|}
\hline $\begin{array}{l}\text { Damage } \\
\text { level }\end{array}$ & Classification & Illustration & Description & Condition \\
\hline- & No damage & & There is no damage. & $\begin{array}{l}\text { It is possible to be used } \\
\text { immediately. }\end{array}$ \\
\hline 1 & $\begin{array}{l}\text { Minor } \\
\text { damage }\end{array}$ & & $\begin{array}{l}\text { There is no significant } \\
\text { structural or non- } \\
\text { structural damage, } \\
\text { possibly only minor } \\
\text { flooding }\end{array}$ & $\begin{array}{l}\text { It is possible to be used } \\
\text { immediately after } \\
\text { minor floor and wall } \\
\text { clean up. }\end{array}$ \\
\hline 2 & $\begin{array}{r}\text { Moderate } \\
\text { damage }\end{array}$ & & $\begin{array}{l}\text { There are slight damages } \\
\text { to non-structural } \\
\text { components. }\end{array}$ & $\begin{array}{l}\text { It is possible to be used } \\
\text { after moderate } \\
\text { reparation. }\end{array}$ \\
\hline 3 & $\begin{array}{l}\text { Major } \\
\text { damage }\end{array}$ & & $\begin{array}{l}\text { There are heavy damages } \\
\text { to some walls but no } \\
\text { damages in columns. }\end{array}$ & $\begin{array}{l}\text { It is possible to be used } \\
\text { after major } \\
\text { reparations. }\end{array}$ \\
\hline 4 & $\begin{array}{r}\text { Complete } \\
\text { damage }\end{array}$ & & $\begin{array}{l}\text { There are heavy damages } \\
\text { to several walls and } \\
\text { some columns. }\end{array}$ & $\begin{array}{l}\text { It is possible to be used } \\
\text { after complete } \\
\text { reparation and } \\
\text { retrofitting. }\end{array}$ \\
\hline 5 & Collapsed & & $\begin{array}{l}\text { There is destructive } \\
\text { damage to walls (i.e., } \\
\text { more than half of wall } \\
\text { density) and several } \\
\text { columns (i.e., bend or } \\
\text { destroyed) }\end{array}$ & $\begin{array}{l}\text { It lost its functionality } \\
\text { (i.e., system collapse). } \\
\text { It is non-reparable or } \\
\text { consumes great cost of } \\
\text { retrofitting. }\end{array}$ \\
\hline 6 & $\begin{array}{l}\text { Washed } \\
\text { away }\end{array}$ & & $\begin{array}{l}\text { The building was washed } \\
\text { away. There is only } \\
\text { foundation remained, } \\
\text { total overturned }\end{array}$ & $\begin{array}{l}\text { It is non-repairable/ } \\
\text { requires total } \\
\text { reconstruction. }\end{array}$ \\
\hline
\end{tabular}


Table 4 Function of building and their definitions

\begin{tabular}{|c|c|c|}
\hline Type & Group & Definition \\
\hline 11 & Residential house & Residential house \\
\hline $12-19$ & Shared accommodation & $\begin{array}{l}\text { Shared accommodation, accommodation with } \\
\text { shop or factory facility included }\end{array}$ \\
\hline $21-29$ & Commercial facility & Commercial facility or operation/service facility \\
\hline $31-39$ & Transportation/storage facility & Transportation/storage facility or industrial plant \\
\hline $41-49$ & Public facility & Multi-purpose or official work \\
\hline $51-59$ & $\begin{array}{l}\text { Agriculture-forestry-aquaculture } \\
\text { facility }\end{array}$ & Agriculture, forestry, or aquaculture facility \\
\hline
\end{tabular}

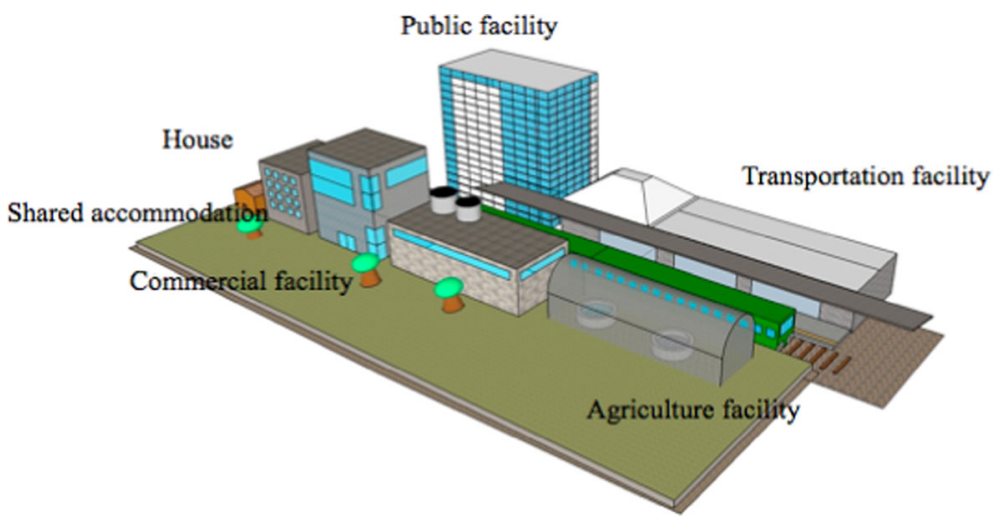

Fig. 2 Illustration of function of building

In Ishinomaki, the tallest damaged building in MLIT's data has fourteen floors. This study uses the metric system (i.e., meter) for the inundation depth. The coastal topography is divided into two types of coast in Ishinomaki city: ria and plain coasts. In this study, the structural material has been categorized into four types: (1) wood, (2) reinforced concrete, (3) steel, and (4) masonry. Similar to Suppasri et al. (2014), the buildings were classified into six functional categories, based on MLIT's classification system: (1) residential houses, (2) shared accommodations, (3) commercial facilities, (4) industrial plants, (5) public facilities, and (6) agriculture-forest-aquaculture facilities. The definition of each category is given in Table 4, and Fig. 2 schematically illustrates the building function.

\section{Data collection and analysis}

\subsection{Data collection}

The detailed data of damage buildings collected during field surveys by MLIT were obtained from Ishinomaki city. There were 68,596 buildings in the dataset (both ria and plain coasts). The tsunami inundation depth of each building shown in the MLIT data was obtained from the Tohoku Earthquake Tsunami Joint Survey Group (2011), the MLIT 
Table 5 Descriptive statistics of floors and inundation depth

\begin{tabular}{llllll}
\hline Item & $N$ & Min & Max & Mean & SD \\
\hline Inundation depth (m) & 32,429 & 0.0 & 20.4 & 2.363 & 2.413 \\
Number of floors & 32,428 & 1 & 14 & 1.740 & 0.566 \\
\hline
\end{tabular}

Table 6 Descriptive statistics of damage level

\begin{tabular}{lrrc}
\hline Damage level & \multicolumn{1}{l}{$N$} & Percent & Cumulative percent \\
\hline No damage & 205 & 0.6 & 0.6 \\
Damage level 1 & 4,500 & 13.9 & 14.5 \\
Damage level 2 & 6,215 & 19.2 & 33.7 \\
Damage level 3 & 7,583 & 23.4 & 57.1 \\
Damage level 4 & 477 & 1.5 & 58.5 \\
Damage level 5 & 7,821 & 24.1 & 82.6 \\
Damage level 6 & 5,628 & 17.4 & 100.0 \\
Total & 32,429 & 100.0 & \\
\hline
\end{tabular}

survey, other survey reports, photos and videos or other visual materials, eyewitness accounts, and other sources.

\subsection{Descriptive statistics}

Although there were 68,596 buildings in the raw dataset, the information was only complete and usable for 32,429 buildings $(47.18 \%$ of the total). The reduction from the original amount of data still allows for extremely large sample sizes to be analyzed, thus does not compromise the power of the following analysis (Green 1991). Table 5 shows the descriptive statistics of inundation depth and the number of floors.

Following the damage level categorization mentioned in Sect. 4, the descriptive statistics of damage level can be seen in Table 6. While the largest group is damage level 5 $(N=7,821 ; 23.4 \%)$, the smallest is damage level $4(N=477 ; 1.5 \%)$, and there are 205 buildings $(0.6 \%)$ reported to have not suffered any damage.

According to Suppasri et al. (2014)'s categorization, Table 7 shows the descriptive statistics of coastal topography. $89.7 \%$ of the buildings are located in the plain coast, and $10.3 \%$ are on the ria coast. Table 8 shows the descriptive statistics of structural material. Wooden buildings form the largest group $(84.3 \%)$. As shown in Table 9, among six functions of building, the largest group is residential houses $(65.3 \%)$, followed by shared accommodation $(21 \%)$, commercial facilities $(6.6 \%)$, transportation/storage facilities $(4.8 \%)$, and public facilities $(1.5 \%)$, and the smallest group is agriculture, forest, and aquaculture facilities $(0.8 \%)$.

\subsection{Testing for correlated predictors}

Before performing regression analysis, it is necessary to check that all predictor variables are independent. Indeed, when predictors are highly correlated, multicollinearity can occur and strongly affect the coefficient estimates of the regression model, making it non-robust 
Table 7 Descriptive statistics of coastal topography

Table 8 Descriptive statistics of Structural Material

Table 9 Descriptive statistics of function of building

\begin{tabular}{lrr}
\hline Coastal topography & \multicolumn{1}{l}{$N$} & Percent \\
\hline Ria coast & 3,331 & 10.3 \\
Plain coast & 29,098 & 89.7 \\
Total & 32,429 & 100.0 \\
\hline
\end{tabular}

\begin{tabular}{lrr}
\hline Structural material & \multicolumn{1}{l}{$N$} & Percent \\
\hline Reinforced concrete & 878 & 2.7 \\
Steel & 2,318 & 7.1 \\
Masonry & 1,883 & 5.8 \\
Wood & 27,350 & 84.3 \\
Total & 32,429 & 100.0 \\
\hline
\end{tabular}

\begin{tabular}{lrr}
\hline Function of building & \multicolumn{1}{l}{ N } & Percent \\
\hline Residential house & 21,165 & 65.3 \\
$\begin{array}{l}\text { Shared accommodation, including accommodation } \\
\quad \text { with shop or factory facility }\end{array}$ & 6,825 & 21.0 \\
Commercial facility or operation/service facility & 2,151 & 6.6 \\
Transportation/storage facility or industrial plant & 1,549 & 4.8 \\
Public facility (i.e., multi-purpose or official work) & 479 & 1.5 \\
Agriculture, forestry, and aquaculture facility & 260 & 0.8 \\
Total & 32,429 & 100.0 \\
\hline
\end{tabular}

to small variations in the predictors (Farrar and Glauber 1967; Katz 2011; Vanichbancha 2006).

A Pearson product-moment correlation coefficient, which is a method to determine the strength of the relationship between two factors (Chan 2003; Kaiyawan 2010; Katz 2011), was computed to assess the relationship between the number of floors, the inundation depth, the coastal topography, the structural material, and the building function. Results are shown in Table 10. While others had no high correlation, according to Chan (2003), the correlation coefficient value showed moderate strong relationship (i.e., correlation coefficient value is more than 0.6 (Chan 2003)) between coastal topography and inundation depth $(r=-0.613)$ at the significance level $p<0.01$, which demonstrates that the relationship is unlikely to happen by chance (Chan 2003). This result was highly expected given that the physics of the inland flow is predominantly driven by land and coastal features. Therefore, coastal topography was eliminated from our analysis.

\subsection{Ordinal regression analysis}

Next, the data were analyzed using ordinal regression. Similar to logistic regression, ordinal regression uses a so-called link function to express the relationship between the linearly related predictors and the mean outcome: Because the logit is the link function typically considered to be adequate for multinomial distributions (Chan 2005; Gelman and 
Table 10 Correlational analysis

\begin{tabular}{|c|c|c|c|c|c|}
\hline & $\begin{array}{l}\text { Inundation } \\
\text { depth }\end{array}$ & $\begin{array}{l}\text { Coastal } \\
\text { topography }\end{array}$ & $\begin{array}{l}\text { Number of } \\
\text { floors }\end{array}$ & $\begin{array}{l}\text { Structural } \\
\text { material }\end{array}$ & $\begin{array}{l}\text { Function of } \\
\text { building }\end{array}$ \\
\hline $\begin{array}{l}\text { Inundation depth: } \\
\text { Pearson corr. }\end{array}$ & 1 & & & & \\
\hline $\begin{array}{l}\text { Coastal topography: } \\
\text { Pearson corr. }\end{array}$ & $-0.613 * *$ & 1 & & & \\
\hline $\begin{array}{l}\text { Number of floors: } \\
\text { Pearson corr. }\end{array}$ & $-0.092 * *$ & $0.118 * *$ & 1 & & \\
\hline $\begin{array}{l}\text { Structural material: } \\
\text { Pearson corr. }\end{array}$ & $-0.016^{* *}$ & $-0.057 * *$ & $-0.202 * *$ & 1 & \\
\hline $\begin{array}{l}\text { Function of building: } \\
\text { Pearson corr. }\end{array}$ & $-0.012 *$ & $-0.028 * *$ & $0.161 * *$ & $0.353 * *$ & 1 \\
\hline
\end{tabular}

** Correlation is significant at $p<0.01$ (2-tailed)

* Correlation is significant at $p<0.05$ (2-tailed)

Hill 2007; Norusis 2010), it was initially selected. The ordinal regression follows the assumption that all categorical outcomes have the same set of parameters. This assumption can be verified using the test of parallel lines (i.e., test whether the coefficient estimates for each variable across categories are all the same) (Chan 2005; Norusis 2010). However, the test of parallel lines showed significance at level $p<0.001$ for the logit link, thus the assumption that all categories contain the same set of parameter was not reasonable. The complementary log-log link (Clog-log) is likely to be a suitable alternative due to its typical application (i.e., higher categories more probable). Therefore, the Clog-log link function was tested in a similar fashion, and the null hypothesis (i.e., the location parameters (slope coefficients) are the same across response categories) could not be rejected. Hence, the Clog-log link function was selected. The buildings with no damage were set to be our reference category for the damage level. For the predictor variables, following Katz (2011)'s suggestion to choose the largest sample size when the hypothesis does not lead to choose a particular category, residential houses were set to be our reference category for function of building and wood was set to be our reference category for structural material.

Here, in order to see the amount of variation in output that can be explained by the predictor variables, the model-fitting statistic, so-called Pseudo- $R^{2}$, was calculated (Chen and Hughes 2004). Based on the methodology from Norusis (2010), the three commonly used Pseudo- $R^{2}$ formulas (Cox and Snell 1989; Nagelkerke 1991; McFadden 1974) of the analysis have been applied. The results showed as follows: $R_{\text {Cox and Snell }}^{2}=0.861 ; R_{\text {Nage- }}$ lkerke $^{2}=0.893 ; R_{\text {McFadden }}^{2}=0.591$. They indicate that at least about $60 \%$ is being explained by this model. It is normal that $R_{\mathrm{McFadden}}^{2}$ tends to be much lower than $R_{\mathrm{Cox}}$ and

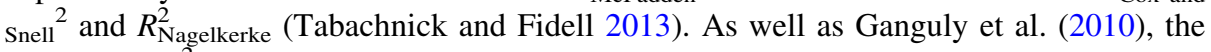
model with $R_{\text {McFadden }}^{2}$ more than 0.4 is considered as very good-fit. The result of the ordinal regression analysis is shown in Table 11. All thresholds (except for the damage level 2) are found to be significant at level $p<0.001$. The results also show that significant explanatory variables include inundation depth $(p<0.001)$, shared accommodation function $(p<0.001)$, commercial facility function $(p<0.01)$, transportation/storage facility 
Table 11 Explanatory variables associated with the damage level based on ordinal regression with the complementary log-log link

\begin{tabular}{|c|c|c|c|}
\hline Item name & Parameter estimate & $p$ & Result \\
\hline Threshold (damage level = 1) & 1.064 & $0.000 * * *$ & Support \\
\hline Threshold (damage level = 2) & -0.016 & 0.522 & Not support \\
\hline Threshold (damage level = 3) & -0.726 & $0.000 * * *$ & Support \\
\hline Threshold (damage level $=4$ ) & -1.591 & $0.000 * * *$ & Support \\
\hline Threshold (damage level = 5) & -1.652 & $0.000 * * *$ & Support \\
\hline Threshold (damage level $=6$ ) & -2.980 & $0.000 * * *$ & Support \\
\hline Inundation depth & -0.423 & $0.000 * * *$ & Support \\
\hline Number of floors & -0.016 & 0.188 & Not support \\
\hline Structural material (category $=$ reinforced concrete) & 0.392 & $0.000 * * *$ & Support \\
\hline Structural material (category = steel) & 0.167 & $0.000 * * *$ & Support \\
\hline Structural material (category = masonry) & 0.006 & 0.807 & Not support \\
\hline Function (category = shared accommodation) & -0.072 & $0.000 * * *$ & Support \\
\hline Function (category $=$ commercial facility) & -0.090 & $0.002 * *$ & Support \\
\hline Function (category $=$ transportation/storage facility) & -0.102 & $0.003 * *$ & Support \\
\hline Function (category = public facility) & -0.007 & 0.898 & Not support \\
\hline Function (category = agriculture facility) & 0.069 & 0.326 & Not support \\
\hline
\end{tabular}

* Significant at level $p<0.05$; $* *$ significant at level $p<0.01 ; * * *$ significant at level $p<0.001$

function $(p<0.01)$, reinforced concrete structural material $(p<0.001)$, and steel structural material $(p<0.001)$.

Since our link function is Clog-log, the general model is formulated as follows (see Norusis 2010):

$$
\begin{aligned}
\ln \left(-\ln \left(1-\gamma_{j}\right)\right)= & {\left[\theta_{j}-\left(\beta_{1} x_{1}+\beta_{2} x_{2}+\beta_{3} x_{3}+\cdots+\beta_{m} x_{m}\right)\right] / \exp \left(\tau_{1} z_{1}+\tau_{2} z_{2}+\tau_{3} z_{3}\right.} \\
& \left.+\cdots+\tau_{n} z_{n}\right)
\end{aligned}
$$

In Eq. (2), $\gamma_{j}$ is the cumulative probability of damage for the $j$ th category $(j=\{1, \ldots, 5\}), \theta_{j}$ is the threshold for the $j$ th category, $x_{i}$ are the predictors, $\beta_{1} \ldots \beta_{m}$ are the $m$ regression coefficients ( $m$ representing the number of predictors), and $\tau_{1} \ldots \tau_{n}$ are $n$ coefficients for the scale component.

If we substitute the significant explanatory variables into Eq. (2), we obtain:

$$
\begin{aligned}
\ln \left(-\ln \left(1-\gamma_{j}\right)\right)= & \left\{\theta_{j}-\left[\beta_{\text {func_shared }} x_{\text {func_shared }}+\beta_{\text {func_comm }} x_{\text {func_comm }}\right.\right. \\
& +\beta_{\text {func_tran }} x_{\text {func_tran }}+\beta_{\text {mat_rc }} x_{\text {mat_rc }} \\
& \left.\left.+\beta_{\text {mat_steel }} x_{\text {func_steel }}\right]\right\} / \exp \left({ }_{\text {depth }} z_{\text {depth }}\right)
\end{aligned}
$$

In Eq. (3), $\beta_{\text {func_shared }}$ is the regression coefficient obtained for the shared accommodation building function, $\beta_{\text {func_comm }}$ is the regression coefficient for the commercial facility building function, $\beta_{\text {func_tran }}$ is the regression coefficient for transportation/storage facilities, $\beta_{\text {mat_rc }}$ is the regression coefficient for the reinforced concrete structural material, $\beta_{\text {mat_steel }}$ is the regression coefficient for the steel structural material, $\tau_{\text {depth }}$ is the scale component [i.e., a component used to account for differences in variability for different values of the predictor variables (Norusis 2010)] coefficient corresponding to inundation depth, 
Table 12 Summary of prediction model

\begin{tabular}{llll}
\hline Damage level & Link function & $\begin{array}{l}\text { Threshold } \\
\Theta_{j}\end{array}$ & Coefficient \\
\hline 1 & $\ln \left(-\ln \left(1-\gamma_{1}\right)\right)$ & 1.064 & $\beta_{\text {mat_rc }}=0.392$ \\
2 & $\ln \left(-\ln \left(1-\gamma_{2}\right)\right)$ & $\mathrm{n} / \mathrm{a}$ & $\beta_{\text {mat_steel }}=0.167$ \\
3 & $\ln \left(-\ln \left(1-\gamma_{3}\right)\right)$ & -0.726 & $\beta_{\text {func_shared }}=-0.072$ \\
4 & $\ln \left(-\ln \left(1-\gamma_{4}\right)\right)$ & -1.591 & $\beta_{\text {func_shared }}=-0.090$ \\
5 & $\ln \left(-\ln \left(1-\gamma_{5}\right)\right)$ & -1.652 & $\tau_{\text {depth }}=-0.423$ \\
6 & $\ln \left(-\ln \left(1-\gamma_{6}\right)\right)$ & -2.980 & \\
\hline
\end{tabular}

$x_{\text {func_shared }}, x_{\text {func_comm }}, x_{\text {func_tran }}, x_{\text {mat_rc }}, x_{\text {func_steel }}$ are the predictor variables (i.e., each $x$ representing a different value of the building function and building material categorical variables), and $z_{\text {depth }}$ is the continuous predictor variable for the scale component as the thresholds and regression coefficient estimate are shown in Table 12.

\subsection{Accuracy of the mean function}

In order to evaluate the accuracy of the model, we applied a cross-tabulating method. The predicted classification and the actual classification are shown in a $5 \times 7$ classification table (Table 13), along with the proportion of correct estimations (in bold). The actual damage-level-1 buildings are estimated correctly for $56.0 \%$ of the buildings $(21.9 \%$ are estimated as damage level 2 and $22.0 \%$ are estimated as damage level 3). $33.0 \%$ are correct for damage level $2(35.1 \%$ are estimated as damage level 1 and $31.8 \%$ are estimated as damage level 3). $68.9 \%$ are correct for damage level 3 (22.0\% are estimated as damage level 2). $55.9 \%$ are correct for damage level 5 (39.2\% are estimated as damage level 3). $48.0 \%$ are correct for damage level 6 (48.3\% are estimated as damage level 5). In general, the model can estimate the actual damage level \pm one damage level. However, the model does not estimate any buildings to be at damage level 4 due to the truly small samples in actual damage level 4 . On the other hand, the actual damage level 4 buildings are estimated as damage level $5(60.8 \%)$.

\subsection{Relative importance of the predictors}

In this section, we aim at finding the explanatory variables which influence the damage level for each structural material, then for each function of building.

\subsubsection{Building material}

A number of studies (Matsutomi and Harada 2010; Reese et al. 2007, 2011; Ruangrassamee et al. 2006; Shuto 1993; Suppasri et al. 2012a, c, 2013; Valencia et al. 2011) showed that the range of inundation depths influences the scale of damage differently when structural material is taken into account (see Table 1). We continued the analysis by using the same method as applied previously but reduced the scope of data into each specific building's structural material in order to check the significant variables which can influence the damage level. Table 14 shows the results from the ordinal regression analysis applied to structural material. Similar to our previous results, the inundation depth is the significant explanatory variable for all structural materials. The number of floors is the significant 


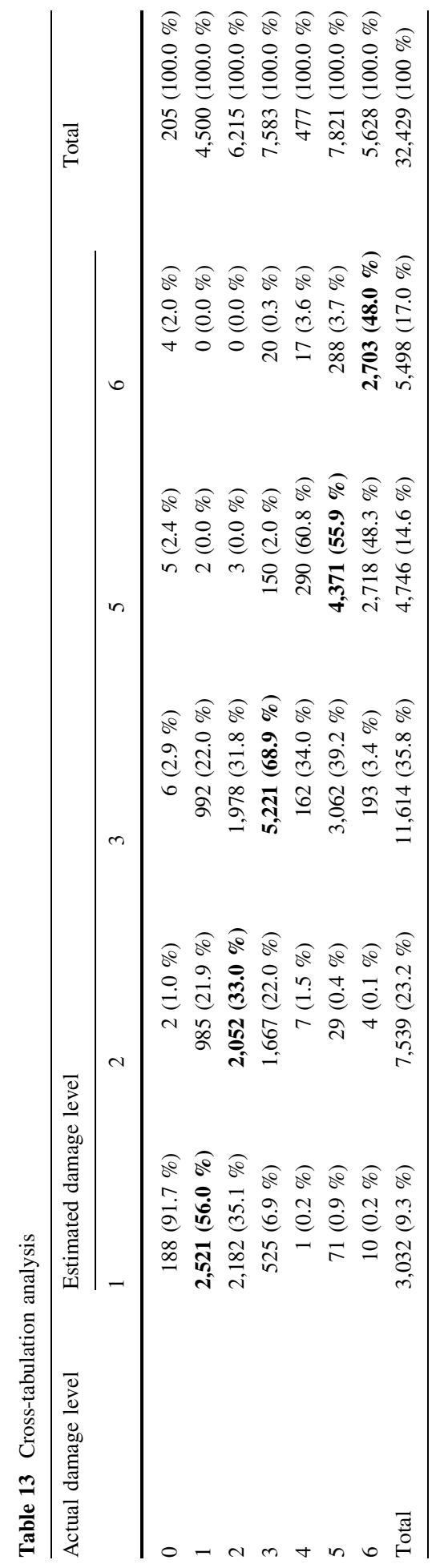


Table 14 Explanatory variables associated with the damage level based on ordinal regression with the complementary log-log link for specific structural material

\begin{tabular}{|c|c|c|c|c|}
\hline \multirow[t]{2}{*}{ Item name } & \multicolumn{4}{|l|}{ Parameter estimate } \\
\hline & Reinforced concrete & Steel & Wood & Masonry \\
\hline Threshold (damage level = 1) & $1.630 * * *$ & $0.917 * * *$ & $1.001 * * *$ & $1.067 * * *$ \\
\hline Threshold (damage level $=2$ ) & $0.544^{* *}$ & 0.050 & $-0.094 * *$ & -0.029 \\
\hline Threshold (damage level $=3$ ) & $-0.816 * * *$ & $-\mathbf{0 . 7 8 0} * * *$ & $-0.772 * * *$ & $-0.848 * * *$ \\
\hline Threshold (damage level $=4$ ) & $-1.520 * * *$ & $-1.544 * * *$ & $-1.654 * * *$ & $-1.714 * * *$ \\
\hline Threshold (damage level $=5$ ) & $-2.630 * * *$ & $-\mathbf{2 . 0 7 9} * * *$ & $-1.655 * * *$ & $-1.719 * * *$ \\
\hline Threshold (damage level $=6$ ) & $-4.718 * * *$ & $-4.432 * * *$ & $-2.928 * * *$ & $-3.082 * * *$ \\
\hline Inundation depth & $-\mathbf{0 . 3 7 9} * * *$ & $-0.499 * * *$ & $-0.421 * * *$ & $-0.461 * * *$ \\
\hline Number of floors & 0.034 & $0.135 * * *$ & $-0.046^{* *}$ & 0.000 \\
\hline Function (shared accommodation) & $0.350 *$ & -0.098 & $-0.084 * * *$ & $-0.143 *$ \\
\hline Function (commercial facility) & 0.190 & -0.142 & -0.076 & -0.175 \\
\hline Function (transportation/storage facility) & -0.260 & $-0.218 *$ & -0.038 & 0.083 \\
\hline Function (public facility) & $0.316^{*}$ & -0.161 & 0.055 & $-0.544 *$ \\
\hline Function (agricultural facility) & $\mathbf{0 . 4 7 8}^{*}$ & -0.113 & 0.016 & 0.145 \\
\hline$R_{\text {Cox and Snell }}^{2}$ & 0.947 & 0.921 & 0.830 & 0.901 \\
\hline$R_{\text {Nagelkerke }}^{2}$ & 0.985 & 0.953 & 0.863 & 0.938 \\
\hline$R_{\text {McFadden }}^{2}$ & 0.905 & 0.746 & 0.546 & 0.715 \\
\hline AccuracyDamageLevel1 (\%) & $\mathrm{n} / \mathrm{a}$ & 18.0 & 61.0 & 32.6 \\
\hline AccuracyDamageLevel2 (\%) & 100.0 & 91.7 & $\mathrm{n} / \mathrm{a}$ & 79.9 \\
\hline AccuracyDamageLevel3 (\%) & $\mathrm{n} / \mathrm{a}$ & 16.6 & 88.4 & 26.0 \\
\hline AccuracyDamageLevel4 (\%) & 39.0 & $\mathrm{n} / \mathrm{a}$ & $\mathrm{n} / \mathrm{a}$ & $\mathrm{n} / \mathrm{a}$ \\
\hline AccuracyDamageLevel5 (\%) & 29.8 & 86.7 & 49.8 & 56.5 \\
\hline AccuracyDamageLevel6 (\%) & 0.0 & 24.2 & 53.3 & 42.5 \\
\hline
\end{tabular}

Bold means that value is significant at level $p<0.05,0.01,0.001$

explanatory variables for only steel and wood buildings $(p<0.001$ and $p<0.01$, respectively). The function of shared accommodation is found to be significant for reinforced concrete $(p<0.05)$, wood $(p<0.001)$, and masonry $(p<0.05)$. The commercial facility function is not a significant explanatory variable for any structural material. The transportation/storage facility function is found to be significant for only steel building $(p<0.05)$. The public facility function is found to be significant for reinforced concrete and masonry buildings ( $p<0.05$ for both of them). The agricultural facility function is found to be significant for only reinforced concrete buildings $(p<0.05)$. The regression coefficients, the Pseudo- $R$-squares, and the accuracy results from the cross-tabulating method are shown in Table 14.

\subsubsection{Building function}

We continued the analysis by using the same method as applied previously, this time reducing the scope of data into each specific building function in order to check the significant variables which can influence the damage level. The results are shown in Table 15. It can be seen that inundation depth is always the significant explanatory variable 
for all functions at level $p<0.001$, while the number of floors is the significant explanatory variables for only shared accommodation and transportation/storage facilities. Furthermore, reinforced concrete is found to be significant for shared accommodation $(p<0.001)$, commercial facilities $(p<0.001)$, and agricultural facilities $(p<0.05)$. Steel is found to be significant for residential houses $(p<0.01)$, shared accommodation $(p<0.001)$, and commercial facilities $(p<0.01)$; finally masonry is found to be significant only for public facilities $(p<0.01)$. The regression coefficients, the Pseudo- $R$ squares, and the accuracy results from the cross-tabulating method are shown in Table 15.

\section{Discussion and conclusion}

\subsection{Discussion}

In line with previous studies (Koshimura et al. 2009b; Matsutomi and Harada 2010; Reese et al. 2007, 2011; Ruangrassamee et al. 2006; Shuto 1993; Suppasri et al. 2012a, c, 2013; Valencia et al. 2011), our model includes and ascertains the inundation depth as one of the significant explanatory variables, together with the structural material (reinforced concrete and steel). The function of buildings (shared accommodation, commercial facility, and transportation/storage facility) is also found to be of importance.

Although the number of floors is found not to be one of the significant explanatory variables when considering the entire dataset, it is found to be significant for wooden and steel buildings (when the data are categorized by structural material) and for shared accommodation and transportation/storage facilities (when the data are categorized by building function) (see Sect. 5.5).

The significance of the number of floors for steel and wood buildings only in relation to their damage state is likely to be explained by the difference in wall resistance to tsunami loads. Referring to Table 3, the description of damage (particularly for high damage levels) is largely based on the amount of damage to walls, proportionally to the size of the structure (e.g., "more than half of wall density" for level 5): In the case of a reinforced concrete or masonry building, walls are made of reinforced concrete/brick, whereas the walls of wood and steel buildings are typically made of weak materials such as ply wood. In addition, wood and steel buildings typically have less than three stories, whereas the range of heights for RC buildings is much broader (up to 14 stories) (see Table 16). This means that for a given inundation depth, the walls of a reinforced concrete/masonry building will likely resist well the hydrostatic and hydrodynamic wave loads, regardless of the number of floors, so the damage level will appear not to be strongly dependent on this variable. On the other hand, under tsunami loading, the walls of wooden and steel buildings will fail very easily, causing proportionally more damage as the flow depth increases and reaches higher floors.

Similarly, the significance of the number of floors for shared accommodation and transportation/storage in relation to their damage state is likely to be a consequence of their dominant structural material. Indeed, we can see that $87 \%$ of shared accommodations and $84 \%$ of transportation/storage facilities are made of wood and steel (shared accommodation: wood $82 \%$ and steel $5 \%$; transportation/storage facilities: wood $31 \%$ and steel $53 \%$ ), which would cause the walls of such structures to be more vulnerable to tsunami forces, against only $50 \%(\operatorname{wood} 31 \%$ and steel $19 \%)$ and $59 \%(\operatorname{wood} 30 \%$ and steel $29 \%$ ) for example for public and agricultural facilities, respectively (see Fig. 3). It should be noted that residential houses, however, primarily made of wood (95\%), have not 


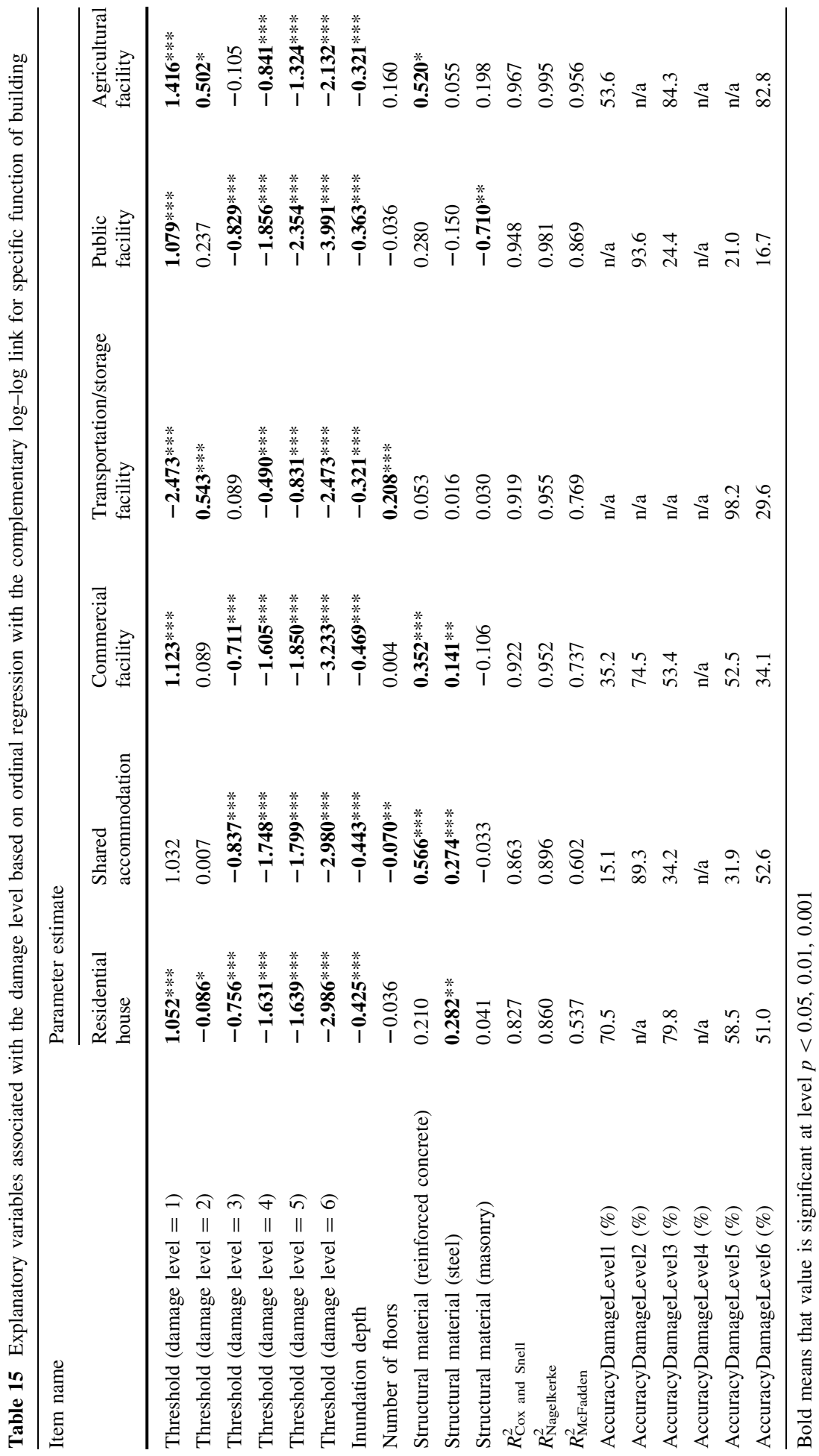


Table 16 Distribution of number of floors of the building in each structural material

\begin{tabular}{lrrrr}
\hline \multirow{2}{*}{ No. of floor } & \multicolumn{4}{l}{ Structural material } \\
\cline { 2 - 5 } & Reinforced concrete & Steel & Masonry & Wood \\
\hline 1 & 59 & 839 & 782 & 8,034 \\
2 & 325 & 1,213 & 1,088 & 19,199 \\
3 & 291 & 239 & 13 & 107 \\
4 & 106 & 24 & 0 & 1 \\
5 & 56 & 2 & 0 & 0 \\
6 & 22 & 1 & 0 & 0 \\
7 & 8 & 0 & 0 & 0 \\
8 & 4 & 0 & 0 & 0 \\
9 & 6 & 0 & 0 & 0 \\
14 & 1 & 0 & 0 & 0 \\
\hline
\end{tabular}

resulted in a statistically significant influence of the number of floors. This is probably due to the extremely large counts of 2-story buildings for this function (4 times the number of single story houses, with an insignificant number of buildings higher than 3 stories) in comparison with shared accommodation and transportation/storage facilities which display a greater spread across the range of heights (see Fig. 4). In other words, a variable which is virtually constant (effectively only takes one value at number of floors $=2$ ), will not appear as significant whereas a greater spread will allow for the effect of this variable to be more apparent, which is the case for these specific building functions.

The cross-tabulation results highlight an interesting issue about the classification standard of the buildings damaged by the tsunami. According to the present findings, the model estimated $60.8 \%$ of the actual damage-level- 4 buildings as damage-level- 5 buildings, and $34 \%$ as being at damage level 3 -which put together is almost the totality of the amount of damage level 4 observations. A closer examination of the definition of this damage level in Table 3 reveals that these two levels are likely to have many similar characteristics: Damage level 4: "heavy damages to several walls and some columns"; Damage level 5: "destructive damage to walls (more than $50 \%$ of wall density) and several columns (bend or destroyed)." Similarly, "Possible to be use after a complete reparation and retrofitting" (damage level 4) can easily be seen as "Possible to be use after major reparations" (damage level 3). Therefore, it is likely that survey teams may have misclassified a lot of buildings being at damage level 4 as having reached damage level 5 , or under-estimated the damage to being at level 3. In light of these observations, it is suggested that the damage level classification may need to be reconsidered to avoid potential judgment errors in future surveys. These levels may need to be combined, redefined, or described in more details to highlight their differences.

\subsection{Conclusions}

This study presented the analysis of the detailed damage data of the buildings impacted by the 2011 tsunami in Ishinomaki by applying ordinal regression to generate a model relating all available predictor variables to the damage level. The accuracy of the results was evaluated by cross-tabulation. This is the first attempt in applying this statistical perspective to buildings damaged by tsunami which combined all significant parameters in one equation. Inundation depth, function of building (shared accommodation, commercial 


\section{Structural Materials for Residential Houses}

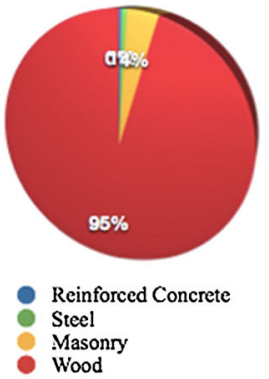

Structural Materials for Commercial Facilities

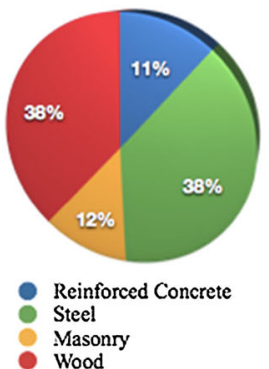

Structural Materials for Shared Accommodations

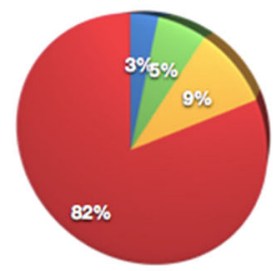

Reinforced Concrete

Steel

Masonry

Wood

Structural Materials for Transportation/storage Facilities

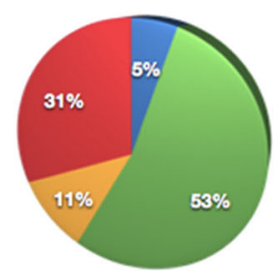

Reinforced Concrete

Steel

Masonry

Wood

\section{Structural Materials for Public Facilities}

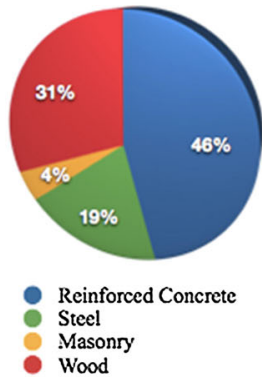

Structural Materials for Agriculture-Forestry-Aquaculture Facilities

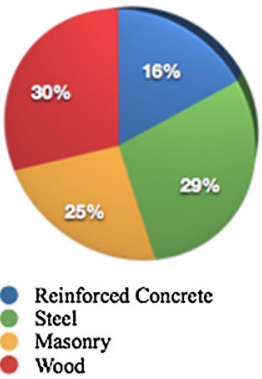

Fig. 3 Structural materials for each function of building

facility, and transportation/storage facility), and structural material (reinforced concrete and steel) have been found to be significant exploratory variables that can influence the damage level of the buildings.

In addition, as mentioned (see Sect. 6.1), the significance of the number of floors is likely to be explained by the difference in wall resistance to tsunami loads. When the data are categorized by structural material, we found that the number of floors is found to be another significant variable for wooded and steel buildings, whose wall resistance is weaker to tsunami loads than reinforced concrete and masonry buildings. Meanwhile, when the data are categorized by building function, the number of floors is also significant for shared accommodation and transportation/storage facilities whose structural material was indeed mostly made by wood and steel. 


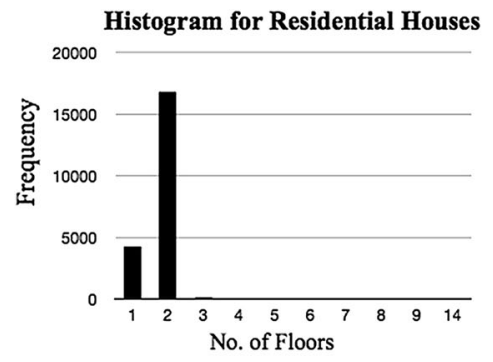

Historgram for Commercial Facilities

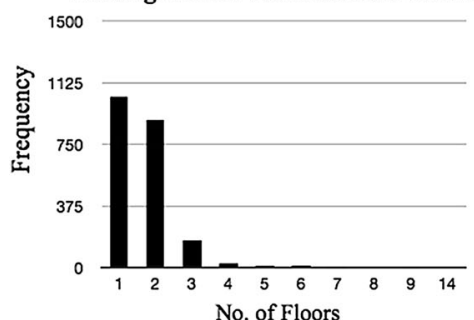

Histogram for Public Facilities

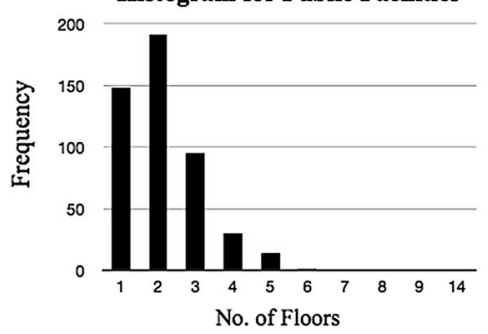

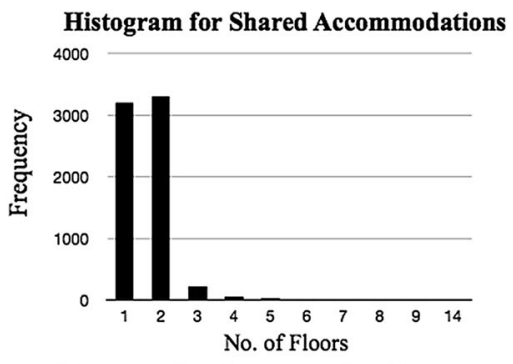

Historgram for Transportation/storage Facilities

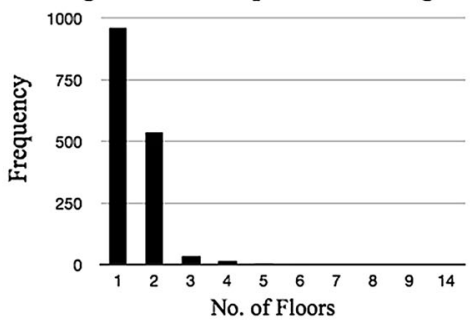

Histogram for Agriculture-forestry-Aquaculture Facilities

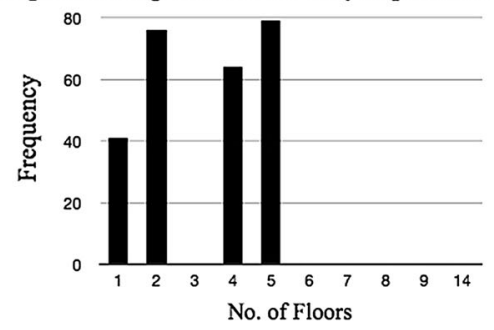

Fig. 4 Histograms for each function of building

The results of this study can contribute to both academic research and industrial or governmental practice. In the context of tsunami research, a new approach has been applied to identify and rank influential variables on the process observed, and a new model for tsunami damage prediction based on the ordinal regression methodology and the extensive database from the 2011 Japan tsunami is proposed. In the field, the prediction model can be applied to predict the damage level when the input variables are known, and its outputs compared with state-of-the-art predictions. The government, urban and disaster planners, engineers, architects, insurance companies, and construction businesses may also take into account such results in the decision making process.

However, it is important to understand the limitations of the aforementioned results to understand their applicability and highlight avenues for improvement. First, this study used only the available data, so the predictive capability of the model to future events and different datasets needs to be improved and evaluated through further analysis. In addition, the observed damage might be influenced by other variables (such as tsunami flow velocity and distance from the shoreline) or other external variables (e.g., floating debris, barrier, and environment). If such data becomes available, it will be possible to include those variables into future analyses and assess their importance, as well as improving the accuracy of estimations. Also, even though we chose the reference variables by following 
the suggestion of Katz (2011), there may be limitation inherent to the choices we made regarding the reference variables (i.e., wood and residential house) whose any variability were not be captured by the model. Finally, despite the large number of points which is considered sufficient to perform the analysis, all buildings were surveyed in one city. Some characteristic setting of the area of study may not be generalized to other areas, and therefore, it is necessary to test this approach with other affected areas and compare results.

Acknowledgments This research was partly funded by the Academy for Co-creative Education of Environment and Energy Science (ACEEES) of Tokyo Institute of Technology, the Ministry of Education, Culture, Sports, Science and Technology (MEXT), the Tokio Marine \& Nichido Fire Insurance Co., Ltd. through the International Research Institute of Disaster Science (IRIDeS) at Tohoku University, and the Willis Research Network under the Pan-Asian/Oceanian tsunami risk modeling and mapping project. The detailed building damage data used in this study were collected during the damage surveys of the 2011 Tohoku tsunami conducted by the Ministry of Land, Infrastructure, Transport and Tourism (MLIT) and were officially provided by Ishinomaki city. The first author also would like to thank Prof. Junichi Iijima and Iijima Laboratory of Tokyo Institute of Technology, Tsunami Engineering Laboratory of Tohoku University, and Dr. Jing Tang.

Open Access This article is distributed under the terms of the Creative Commons Attribution License which permits any use, distribution, and reproduction in any medium, provided the original author(s) and the source are credited.

\section{References}

Bender R, Grouven U (1997) Ordinal logistic regression in medical research. J R Coll Phys Lond 31:546-551

Centre for Research on the Epidemiology of Disaster (CRED) (2013) EM-DAT: The international disaster database. http://www.emdat.net Accessed 31 January 2013

Chan YH (2003) Biostatistics 104: correlation analysis. Singap Med J 44:614-619

Chan YH (2005) Biostatistics 305: multinomial logistic regression. Singap Med J 46:259-269

Charvet I, Suppasri A, Imamura F (2014) Empirical fragility analysis of building damage caused by the 2011 Great East Japan tsunami in Ishinomaki City using ordinal regression, and influence of key geographical features. Stoch Env Res Risk A. doi:10.1193/053013EQS138M

Chen C, Hughes J Jr (2004) Using ordinal regression model to analyze student satisfaction questionnaires. IR Appl 1:1-12

Cox DR, Snell EJ (1989) The analysis of binary data, 2nd edn. Chapman and Hall, London

Crewson P (2006) Applied statistics handbook. AcaStat Software, Leesburg

Dall'Osso F, Gonella M, Gabbianelli G, Withycombe G, Dominey-Howes D (2009a) A revised (PTVA) model for assessing the vulnerability of buildings to tsunami damage. Nat Hazards Earth Syst Sci 9:1557-1565

Dall'Osso F, Gonella M, Gabbianelli G, Withycombe G, Dominey-Howes D (2009b) Assessing the vulnerability of buildings to tsunami in Sydney. Nat Hazards Earth Syst Sci 9:2015-2026

Farrar DE, Glauber RR (1967) Multicollinearity in regression analysis: the problem revisited. Rev Econ Stat 49:92-107

Ganguly I, Koebel T, Cantrell RA (2010) A categorical modeling approach to analyzing new product adoption and usage in the context of the building-materials industry. Technol Forecast Soc 77:662-677

Gelman A, Hill J (2007) Data analysis using regression and multilevel/hierarchical models. Cambridge University Press, New York

Gokon H, Koshimura S (2012) Mapping of building damage of the 2011 Tohoku earthquake and tsunami in Miyagi prefecture. Coast Eng J 54:1250006

Gokon H, Koshimura S, Matsuoka M, Namegaya Y (2011) Developing tsunami fragility curves due to the 2009 tsunami disaster in American Samoa. J Jpn Soc Civ Eng 67:I_1321-I_1325

Green SB (1991) How many subjects does it take to do a regression analysis? Multivar Behav Res 26:499-510

Kaiyawan Y (2010) Principles of statistic and application SPSS (in Thai). Chulalongkorn University Press, Bangkok 
Katz MH (2011) Multivariable analysis: a practical guide for clinical and public health researchers, 3rd edn. Cambridge University Press, New York

Koshimura S, Kayaba S (2010) Tsunami fragility inferred from the 1993 Hokkaido Nansei-oki earthquake tsunami disaster. J Jpn As Earthq Eng 10:87-101

Koshimura S, Matsuoka M, Kayaba S (2009a) Tsunami hazard and structural damage inferred from the numerical model, aerial photos and SAR imageries. In Proceedings of the 7th international workshop on remote sensing for post disaster response, Texas, USA, 22-23 Oct 2009

Koshimura S, Namegaya Y, Yanagisawa H (2009b) Tsunami fragility a new measure to identify tsunami damage. J Disaster Res 4:479-488

Koshimura S, Oie T, Yanagisawa H, Imamura F (2009c) Developing fragility curves for tsunami damage estimation using numerical model and post-tsunami data from Banda Aceh, Indonesia. Coast Eng J 51:243-273

Lall R, Campbell MJ, Walters SJ, Morgan K (2002) A review of ordinal regression models applied on health-related quality of life assessments. Stat Methods Med Res 11:49-67

Mas E, Koshimura S, Suppasri A, Matsuoka M, Matsuyama M, Yoshii T, Jimenez C, Yamazaki F, Imamura F (2012) Developing tsunami fragility curves using remote sensing and survey data of the 2010 Chilean tsunami in Dichato. Nat Hazards Earth Syst Sci 12:2689-2697

Matsutomi H, Harada K (2010) Tsunami-trace distribution around building and its practical use. In: Proceedings of the 3rd international tsunami field symposium, Sendai, Session 3-2

McFadden D (1974) Conditional logit analysis of qualitative choice behavior. In: Zarembka P (ed) Frontiers in economics. Academic Press, New York, pp 105-142

Muora O, Nakazato H (2010). Vulnerability functions for buildings based on damage survey data in Sri Lanka after the 2004 Indian Ocean tsunami. In: Proceedings of the 7th international conference of sustainable built environment, ICSBE, Kandy, pp 371-378, 13-14 Dec 2010

Nagelkerke NJD (1991) A note on the general definition of the coefficient of determination. Biometrika 78:691-692

National Police Agency (2011) Damage condition of the 2011 earthquake off the Pacific coast of Tohoku. http://www.npa.go.jp/archive/keibi/biki/higaijokyo.pdf. Accessed 26 July 2013

Norusis MJ (2010) PASW statistics 18.0 advanced statistical procedures. Prentice Hall Press, Upper Saddle River

Osborne J, Waters E (2002) Four assumptions of multiple regression that researchers should always test. Pract Assess Res Eval 8(2). http://ericae.net/pare/getvn.asp?v=8\&n=2

Papathoma M, Dominey-Howes D (2003) Tsunami vulnerability assessment and its implications for coastal hazard analysis and disaster management planning, Gulf of Corinth, Greece. Nat Hazards Earth Syst Sci 3:733-747

Papathoma M, Dominey-Howes D, Zong Y, Smith D (2003) Assessing tsunami vulnerability, an example from Herakleio, Crete. Nat Hazards Earth Syst Sci 3:377-389

Reese S, Cousins WJ, Power WL, Palmer NG, Tejakusuma IG, Nugrahadi S (2007) Tsunami vulnerability of buildings and people in South Java-field observations after the July 2006 Java tsunami. Nat Hazards Earth Syst 7:573-589

Reese S, Bradley BA, Bind J, Smart G, Power W, Sturman J (2011) Empirical building fragilities from observed damage in the 2009 South Pacific tsunami. Earth Sci Rev 107:156-173

Ruangrassamee A, Yanagisawa H, Foytong P, Lukkunaprasit P, Koshimura S, Imamura F (2006) Investigation of tsunami-induced damage and fragility of buildings in Thailand after the December 2004 Indian Ocean tsunami. Earthq Spectra 22:377-401

Seber GAF (1977) Linear regression analysis. Wiley, New York

Shuto N (1993) Tsunami intensity and disasters. In: Tinti S (ed) Tsunamis in the world. Kluwer, Dortrecht, pp 197-216

Suppasri A, Koshimura S, Imamura F (2011) Developing tsunami fragility curves based on the satellite remote sensing and the numerical modeling of the 2004 Indian Ocean tsunami in Thailand. Nat Hazards Earth Syst Sci 11:173-189

Suppasri A, Koshimura S, Imai K, Mas E, Gokon H, Muhari A, Imamura F (2012a) Damage characteristic and field survey of the 2011 Great East Japan tsunami in Miyagi Prefecture. Coast Eng J 54:1250005$1-1250005-30$

Suppasri A, Koshimura S, Matsuoka M, Gokon H, Kamthonkiat D (2012b) Remote sensing of planet earth: application of remote sending for tsunami disaster. In: Chemin Y (ed) Remote sensing of planet earth. InTech, New York, pp 143-168

Suppasri A, Mas E, Koshimura S, Imai K, Harada K, Imamura F (2012c) Developing tsunami fragility curves from the surveyed data of the 2011 Great East Japan tsunami in Sendai and Ishinomaki plains. Coast Eng J 54:1250008-1-1250008-16 
Suppasri A, Mas E, Charvet I, Gunasekera R, Imai K, Fukutani Y, Abe Y, Imamura F (2013) Building damage characteristics based on surveyed data and fragility curves for the 2011 Great East Japan tsunami. Nat Hazards 66:319-341

Suppasri A, Charvet I, Imai K, and Imamura F (2014) Fragility curves based on data from the 2011 Great East Japan tsunami in Ishinomaki city with discussion of parameters influencing building damage. Earthq Spectra. doi:10.1193/053013EQS138

Sutton AJ, Abrams KR, Jones DR, Sheldon TA, Song F (2000) Methods for meta-analysis in medical research. Wiley, Chichester

Tabachnick BG, Fidell LS (2013) Using multivariate statistics, 6th edn. Pearson Education, Boston

Valencia N, Gardi A, Gauraz A, Leone F, Guillannde R (2011) New tsunami damage functions developed in the framework of SCHEMA project: application to European-Mediterranean coasts. Nat Hazards Earth Syst Sci 11:2385-2846

Vanichbancha K (2006) Data analysis with SPSS for Windows (in Thai). Chulalongkorn University Press, Bangkok 